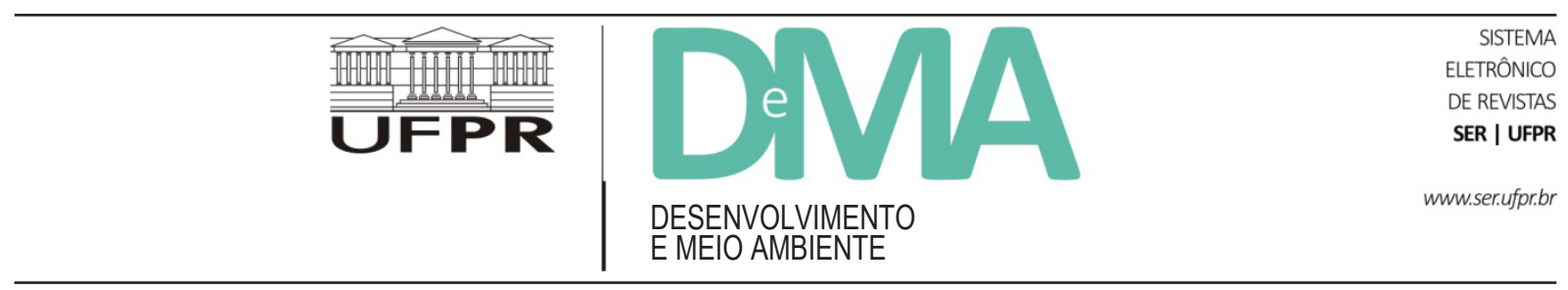

\title{
Cadeias produtivas do carvão vegetal na agricultura familiar no sul do Brasil ${ }^{1}$
}

\section{The Charcoal Supply Chains in the Family Farming in the South of Brazil}

\author{
Marina CARRIERI-SOUZA ${ }^{1 *}$, Alfredo Celso FANTINI ${ }^{1}$, Cíntia ULLER-GÓMEZ², Reney DOROW ${ }^{3}$ \\ ${ }^{1}$ Universidade Federal de Santa Catarina (UFSC), Florianópolis, SC, Brasil. \\ ${ }^{2}$ Fundação do Meio Ambiente de Santa Catarina (FATMA), Florianópolis, SC, Brasil. \\ ${ }^{3}$ Empresa de Pesquisa Agropecuária e Extensão Rural de Santa Catarina (EPAGRI), Florianópolis, SC, Brasil. \\ *E-mail de contato: marina.carrieri@ufsc.br
}

Artigo recebido em 27 de outubro de 2013, versão final aceita em 18 de fevereiro de 2014.

RESUMO A produção de carvão vegetal é uma importante atividade geradora de renda para agricultores familiares no Sul do Brasil, porém, esta relevância não é reconhecida oficialmente. Grande parte do carvão vegetal encontrado nos estabelecimentos varejistas é produzida de forma clandestina. No mercado, o carvão produzido de forma social e ambientalmente responsável pode ser confundido com o carvão produzido em contextos não desejáveis. Procuramos compreender as condições de produção do carvão vegetal na agricultura familiar e como esta chega ao consumidor final, tendo como base o conceito de cadeias produtivas. Realizamos o estudo de três casos representativos no Sul do Brasil, nos municípios de Biguaçu-SC, Santa Rosa de Lima-SC e Bituruna-PR. As ferramentas de coleta de dados foram questionários, entrevistas e conversas informais com atores de todos os elos das cadeias de produção e com técnicos de órgãos ambientais e de extensão rural, além de observação direta nas comunidades. Identificamos no município de Biguaçu as cadeias longa, curta face a face, curta de proximidade espacial e curta espacialmente estendida. Nos municípios de Bituruna e Santa Rosa de Lima identificamos apenas as cadeias longas. São apresentadas diversas normas implícitas que orientam a conduta dos atores sociais. Discute-se a comercialização de carvão em cadeias curtas como forma de criar estratégias de inserção no mercado e agregação de valor com base na identificação das características de qualidade do produto, mas, sobretudo, com destaque para o atendimento aos requisitos ambientais da produção, contribuindo para a produção sustentável na agricultura familiar.

Palavras-chave: agroenergia; comercialização; carvão vegetal; cadeias produtivas; agricultura familiar.

\footnotetext{
${ }^{1}$ Este trabalho apresenta parte dos resultados da dissertação de mestrado da primeira autora e contou com apoio financeiro do CNPq (processo 558703/2009-7, FAPESC (Processo 5287/2011-6), CAPES e CAPES/REUNI. Está inserido na Rede Sul Florestal, que é um projeto interdisciplinar e interinstitucional financiado pelo Conselho Nacional de Desenvolvimento Científico e Tecnológico (CNPq) e pela Fundação de Amparo à Pesquisa e Inovação do Estado de Santa Catarina (FAPESC), por meio do Edital 22/2010 REPENSA. É coordenado pela EPAGRI em parceria com o Núcleo de Florestas Tropicais do Centro de Ciências Agrárias da Universidade Federal de Santa Catarina (NFT/CCA/UFSC), com o Departamento de Florestas da Universidade Federal do Paraná (UFPR), com o Centro de Agroveterinária da Universidade do Estado de Santa Catarina (CAV/UDESC) e com o Instituto Chico Mendes de Conservação da Biodiversidade (ICMBio).
} 
ABSTRACT The charcoal production is an important income generating activity for family farmers in the south of Brazil, but this relevance is not officially recognized. Much of the charcoal found in retail establishments is produced clandestinely. In the market, the coal produced in a socially and environmentally responsible way can be confused with the coal produced in undesirable contexts. We seek to understand the conditions of charcoal production in family farms and how this production comes to the final consumer, based on the concept of supply chains. We conducted a study of three representative cases in southern Brazil, in the cities of Biguaçu, SC, Santa Rosa de Lima, SC and Bituruna, PR. The tools for data collection were questionnaires, interviews and informal conversations with actors of all links of the production chain and with technicians from environmental agencies and rural extension, as well as direct observation in communities. In the municipality of Biguaçu, we identified long, short face-to-face, short with spatial proximity and short spatially extended chains. In the municipalities of Bituruna and Santa Rosa de Lima, we identify only the long chains. We discuss about the several implicit norms that guide the behavior of social actors, identifying the marketing of coal in short chains as a way of creating strategies for entering the market and add value, based on the identification of the quality characteristics of the product, with emphasis on the compliance with the requirements of environmental production obtained in family farming.

Keywords: agroenergy; commercialization; charcoal; supply chains; family farming

\section{Considerações iniciais}

Neste artigo, temos o objetivo de descrever as cadeias produtivas do carvão vegetal na agricultura familiar no Sul do Brasil, contribuindo para o desvelamento dessa questão socioambiental que tem sido deixada à margem de instituições de pesquisa e extensão e dos órgãos ambientais.

A produção de carvão vegetal é uma importante atividade geradora de renda para agricultores familiares. Algumas pesquisas têm apontando para a importância dessa atividade em Santa Catarina (Uller-Gómez \& Gartner, 2008; Steenbock, 2009; Fantini et al., 2010; Lindemann, 2010).

No município de Biguaçu/SC, pesquisa realizada em seis comunidades revelou que o carvão vegetal é a principal fonte de renda para, pelo menos, $30 \%$ das famílias que vivem da agricultura (Uller-Gómez \& Gartner, 2008). Da mesma forma, sabemos da importância da atividade carvoeira para agricultores familiares dos municípios de Calmon e Matos Costa, na mesorregião do Oeste catarinense (Steenbock, 2009). Também Lindemann (2010) identificou a produção de carvão como uma importante fonte de renda para agricultores familiares que vivem em assentamentos rurais de diversos municípios de Santa Catarina.

Apesar disto, os dados do Instituto Brasileiro de Geografia e Estatística - IBGE, para o ano de 2008, não apontam produção de carvão na microrregião de Florianópolis, que abrange o município de Biguaçu/ SC. Da mesma forma, dados do Levantamento Agropecuário Catarinense - LAC - fornecidos pelo Centro de Socioeconomia e Planejamento Agrícola da Empresa de Pesquisa Agropecuária Catarinense, EPAGRI/CEPA, também não acusaram produção de carvão em comunidades do município de Biguaçu (Carrieri-Souza, 2010).

Os dados do IBGE (2008) confirmam a existência de produção de carvão vegetal nos Estados de Santa Catarina e do Paraná, sendo que a produção anual para estes Estados é de, respectivamente, 4.885 t e 169.933 t. No que se refere a Santa Catarina, esses dados, se confrontados com resultados de pesquisas científicas que retrataram a atividade carvoeira (Uller-Gómez \& Gartner, 2008; Steenbock, 2009; Fantini et al., 2010; Lindemann, 2010), parecem subestimar o volume de produção real de carvão no Estado.

Em um nível de abrangência maior, os dados do IBGE e da Organização das Nações Unidas para Agricultura e Alimentação (FAO) divergem quanto à produção anual brasileira de carvão vegetal. Segundo os dados do IBGE (2008), a produção anual de carvão vegetal no Brasil em 2009 foi 1.639.779 t; já os dados da FAO para o mesmo ano indicam uma produção de 5.058.000 t (FAOSTAT, 2011), mais de três vezes o valor indicado pelo IBGE. Assim, apesar da importância econômica e social da produção de carvão vegetal, esta é precariamente avaliada pelas instituições oficiais. 
Podemos perceber que a falta de dados consistentes sobre a produção de carvão vegetal está relacionada ao fato de que a grande maioria dos agricultores realiza a atividade de forma não regulamentada (Uller-Gómez \& Gartner, 2008; Carrieri-Souza, 2010; Fantini et al., 2010).

A realidade da produção de carvão vegetal é normalmente desconhecida de seus consumidores em geral e comumente está associada à ideia de destruição ambiental e exploração de trabalhadores em sistemas de produção de larga escala. De fato, existem relatos de produção de carvão vegetal com estas características no Brasil (Dias et al., 2002; SINCAL et al., 2000).

Entretanto, no Sul do Brasil trabalhos apontam a produção de carvão como uma importante atividade geradora de renda para famílias de agricultores familiares, cuja produção é realizada no estabelecimento rural, em conjunto com outras atividades agrícolas (Uller-Gómez \& Gartner, 2008; Steenbock, 2009; Fantini et al., 2010; Lindemann, 2010). No município de Biguaçu, na Grande Florianópolis, em Santa Catarina, a produção de carvão vegetal faz parte de um sistema de uso da terra tradicional, em que está associada ao cultivo de culturas anuais como aipim e feijão (Uller-Gómez \& Gartner, 2008; Carrieri-Souza, 2010; Fantini et al., 2010).

Apesar da clandestinidade, o carvão vegetal é disponível para compra em estabelecimentos varejistas. A realidade da produção de carvão vegetal é, normalmente, desconhecida dos consumidores em geral e dos próprios órgãos oficiais de pesquisa, extensão e das agências ambientais. Atualmente, no mercado, podemos encontrar carvão produzido em diferentes contextos. Assim, o carvão produzido de forma ambiental e socialmente aceitável acaba se confundindo, nas prateleiras dos supermercados, com o carvão produzido em contextos de destruição ambiental e exploração de trabalhadores, a exemplo dos relatados por Dias (2002) e SINCAL et al. (2000).

A clandestinidade gera diversos problemas para a agricultura familiar, tais como falta de assistência técnica para os produtores e vendedores de carvão; falta de perspectiva de solucionar problemas de insalubridade relacionados ao esforço físico, ergonomia e ao processo de carbonização, entre outros fatores; agricultores com baixa autoestima e medo dos órgãos fiscalizadores, su- jeitos a multas e apreensões (Uller-Gómez \& Gartner, 2008; Carrieri-Souza, 2010).

De forma preliminar, é possível afirmar que os problemas relacionados à produção de carvão vegetal e ao manejo de vegetação nativa se repetem em mais regiões do Estado de Santa Catarina e do Sul do Brasil, contribuindo para um círculo vicioso em que são resultado da clandestinidade, ao mesmo tempo que a agravam e, dessa forma, contribuem para a imprecisão do volume de produção apresentado nos dados oficiais - a produção irregular e o produto clandestino são ocultados pelos agricultores. A falta de regulamentação da atividade está vinculada, principalmente, à dificuldade dos agricultores em obterem informações sobre os processos necessários. Podemos citar também a dificuldade relacionada à falta de regularização fundiária da propriedade, que é pré-requisito para a regularização ambiental. A regularização fundiária, por sua vez, tem custos (serviços de georreferenciamento e judiciais) com os quais poucos agricultores conseguem arcar.

A falta de dados oficiais faz com que a existência e a importância da atividade carvoeira continuem não sendo reconhecidas e, consequentemente, não são pensadas políticas públicas e legislações voltadas para esta realidade. Assim, da mesma forma que a clandestinidade faz com que os dados oficiais não sejam reais, a falta de dados oficiais confiáveis contribui para que a situação de clandestinidade continue e os agricultores permaneçam desassistidos, criando, desta forma, um círculo vicioso.

Levando em conta que os dados sobre produção de carvão vegetal no Sul do Brasil estão subestimados, que existem informações contraditórias sobre o volume de produção e que o carvão vegetal que, muitas vezes, é produzido de forma clandestina pode ser comprado pelos consumidores finais sem dificuldade, este trabalho buscou entender em que condições este carvão é produzido, no Sul do Brasil, e de que forma chega até os seus consumidores, por meio de contextos representativos da agricultura familiar.

Para tanto, lançamos mão do conceito de cadeia produtiva, emprestado da discussão de cadeias agroalimentares, que permite compreender com clareza todos os processos envolvidos ao longo da produção, de forma interligada. 


\section{Cadeias produtivas}

Batalha e Silva (2007) apresentam a cadeia de produção como a soma de todas as operações de produção e de comercialização para passar de uma ou várias matérias-primas de base a um produto final, até que um produto chegue às mãos de seu usuário. $\mathrm{O}$ mesmo autor define o conceito de cadeia de produção como estando dentro de uma ótica técnico-econômica e ressalta que não é somente uma ferramenta de descrição técnica, mas também uma ferramenta de análise econômica (2007).

De acordo com Batalha e Silva (2007), uma cadeia de produção pode ser analisada por meio do encadeamento de suas Unidades Socioeconômicas de Produção - USEPs. Estas unidades asseguram o funcionamento do sistema no qual estão inseridas e têm a capacidade de influenciar e serem influenciadas por esse sistema. Dessa forma, entende-se como Unidade Socioeconômica de Produção cada estabelecimento responsável por um ou mais processos de uma cadeia de produção. Essas unidades estão distribuídas dentro da cadeia de produção em três diferentes macrossegmentos propostos pelos autores. Os três macrossegmentos propostos são:

1. Comercialização: Representa as empresas que estão em contato com o cliente final da cadeia de produção e que viabilizam o consumo e o comércio dos produtos finais (supermercados, mercearias, restaurantes, cantinas, etc.). Podem ser incluídas neste macrossegmento as empresas responsáveis somente pela logística de distribuição.

2. Industrialização: Representa as firmas responsáveis pela transformação das matérias-primas em produtos finais destinados ao consumidor. O consumidor pode ser uma unidade familiar ou uma agroindústria.

3. Produção de matérias-primas: Reúne as firmas que fornecem as matérias-primas iniciais para que outras empresas avancem no processo de produção do produto final (agricultura, pecuária, pesca, piscicultura, etc.). (Batalha \& Silva, 2007, p. 7, grifo nosso).

Nos produtos de origem florestal madeireira nos importa conhecer desde o sistema de obtenção da matéria-prima até a comercialização do produto final, compreendendo, assim, qual a influência ambiental e social da produção de determinado produto.

Diante do entendimento de que a noção de cadeia produtiva (longa) não dava conta de explicar todas as formas de comercialização, Marsden et al. (2000) propuseram a noção de cadeia curta, em complementação à abordagem proposta pelos estudos das cadeias longas. Esta diferenciação diz respeito ao grau de reconhecimento do consumidor final sobre a origem e o sistema de produção e não à distância do local de produção até o local do varejo (Marsden et al., 2000). Com a noção de cadeia curta, os autores atentam para aspectos como território, relações de confiança e credibilidade, que não eram objeto de análise na cadeia longa.

Em uma cadeia longa de produção, os produtos são padronizados para facilitar a distribuição em larga escala, assim, os produtos de vários produtores diferentes são embalados de forma padronizada, impossibilitando a distinção de origem do produto. Na maior parte das vezes, as condições de produção são desconhecidas pelos consumidores.

De forma oposta, nas cadeias curtas, os consumidores têm consciência da origem e da identidade do produto consumido. Segundo Marsden et al. (2000), a característica-chave das cadeias curtas de produção é sua capacidade de aproximar os consumidores e os produtores. As cadeias curtas de produção são definidas por meio da localização territorial ou de um produtor específico. As cadeias curtas têm ganhado maior atenção com a preocupação crescente com a qualidade dos alimentos consumidos e com a associação cada vez maior do "local" e do "natural" com o alimento saudável (Marsden et al., 2000).

O conceito de cadeia curta é importante porque nos permite destacar quando os consumidores identificam a qualidade do produto final com sua origem e com características de produção. Desta forma, podem ser traçadas estratégias de comercialização a partir das diferenciações identificadas.

Marsden et al. (2000) elencam três tipos de cadeias curtas de produção: face a face, de proximidade espacial e espacialmente estendida.

A cadeia face a face acontece quando o consumidor adquire o produto diretamente do produtor ou 
processador; neste caso, a autenticidade e a confiança são geradas por meio da interação pessoal.

A cadeia curta de proximidade espacial ocorre quando os produtos são produzidos e comercializados nas regiões específicas e os consumidores estão cientes da natureza local do produto no ponto de varejo; são exemplos de cadeia de proximidade espacial as vendas de produtos em festas típicas e rotas turísticas.

A cadeia curta espacialmente estendida ocorre quando os valores e informações das localidades de produção são traduzidos aos consumidores que estão distantes do local de produção. Esta proximidade pode não ser espacial e um exemplo claro de cadeia curta espacialmente estendida está nos serviços de rastreabilidade, selos de origem e identidades regionais.

Nesta pesquisa, este referencial nos permitiu compreender de que forma o carvão produzido na agricultura familiar chega ao seu consumidor, verificar como é produzido e como é obtida sua matéria-prima.

\section{Estratégia de pesquisa e ferramentas de coleta de dados}

A estratégia de pesquisa utilizada foi a de estudos de casos nos municípios de Biguaçu e Santa Rosa de Lima, em Santa Catarina, e Bituruna, no Paraná. Esta estratégia é considerada a mais adequada para se compreender os fenômenos das organizações da economia (mercados, empresas e instituições) e sua complexidade e é particularmente útil quando é difícil separar o fenômeno estudado e o contexto (Yin, 2005). O estudo de caso é apropriado para responder questões do tipo como e por que (Roese, 1998; Yin, 2005).

Este trabalho consiste de um estudo de múltiplos casos, em que serão analisados três deles. A análise de múltiplos casos, como já discorrido por Yin (2005), trará mais variáveis ao trabalho e assim haverá maiores possibilidades para comparação entre os dados. A comparação dos dados entre si seguirá a lógica do contraste de contextos e será contraposta com os conceitos teóricos existentes no princípio das generalizações analíticas.

A definição das localidades que constituíram cada "caso" deste trabalho foi definida pela equipe da Rede Sul Florestal (RSF) com base em informações prelimi- nares que apontavam para três contextos com aparentes diferenças na produção de carvão, com a intenção de abranger distintas realidades possíveis para o Sul do Brasil. Desta forma, a proposta de trabalho da RSF vai ao encontro do que propõe Yin (2005) quando afirma que, em um estudo de múltiplos casos, cada caso deve ser cuidadosamente selecionado de forma prever resultados semelhantes, ou contrastantes.

Esta pesquisa teve no seu cerne uma abordagem qualitativa, mas a discussão também estará embasada em dados quantitativos. Os dados quantitativos foram obtidos por meio de questionários estruturados que foram aplicados no âmbito da RSF e utilizados em todos os trabalhos realizados pela RSF. Já os dados qualitativos foram obtidos por meio de entrevistas semiestruturadas, conversas informais e de observação direta, específicos para esta pesquisa.

A abordagem inicial nas comunidades se deu, principalmente, por intermédio de líderes comunitários ou agentes de extensão rural. Em um segundo momento, os agricultores que foram se inserindo no projeto nos apresentaram a outros agricultores. Segundo Yin (2005), esse tipo de prática favorece que o entrevistado adquira um caráter real de informante ao invés de meramente respondente. Além disso, a imersão na comunidade é favorecida quando temos a possibilidade de nos inserirmos nela por intermédio de seus próprios membros.

A elaboração do questionário foi coordenada pela equipe do Subprojeto 2 (Socioeconomia e Gestão da Produção) da RSF, com a participação dos autores deste trabalho, de forma a servir de base para trabalhos mais aprofundados de todos os subprojetos da RSF. Os questionários foram aplicados no período de abril a agosto de 2012, por integrantes da RSF e pelos autores deste trabalho. Antes da aplicação desses questionários, todos os aplicadores participaram de capacitação apropriada e específica para esta atividade. Ao todo foram aplicados 72, sendo 24 em Biguaçu, 25 em Santa Rosa de Lima e 23 em Bituruna. O número de famílias submetidas à aplicação dos questionários foi o número de famílias que foram identificadas e acessíveis nas comunidades pesquisadas. Não é possível definir qual a porcentagem da amostra no universo estudado, pois não há dados oficiais precisos sobre produção carvoeira nas localidades estudadas. No município de Biguaçu, os questionários 
e entrevistas foram realizados principalmente na Microbacia de São Mateus e regiões limítrofes. No município de Santa Rosa de Lima, as entrevistas foram realizadas nas comunidades Mata Verde, Santo Antônio, Nova Esperança, Santa Bárbara, Rio dos Índios e Rio do Meio. No município de Bituruna, os dados foram coletados no Assentamento Sonho de Rose.

Os períodos de coleta de dados na forma de entrevista para os casos nos municípios de Biguaçu, Santa Rosa de Lima e Bituruna foram, respectivamente, outubro/2010, julho-dezembro/2012 e março/2013.

\section{Processos da cadeia produtiva do carvão vegetal}

Com base nos macrossegmentos propostos por Batalha e Silva (2007), destacamos, na Figura 1, os principais processos encontrados nas cadeias produtivas do carvão vegetal observados nesta pesquisa.

O segmento produção de matéria-prima reúne os responsáveis pela produção da lenha que pode ser, ou não, realizada pelo mesmo ator que faz a produção do carvão vegetal. O segmento de industrialização reúne os responsáveis pela produção do carvão vegetal, por sua seleção e pela colocação de embalagem. Para melhor compreensão, dividimos este macrossegmento em duas partes: produção de carvão e seleção e embalagem, pois estes podem ser realizados por diferentes unidades socioeconômicas e dessa maneira essa separação ajudará a ilustrar, mais adiante, as relações entre essas unidades e entre seus atores.

Já a seleção e a embalagem são realizadas geralmente na mesma unidade. Por este motivo, são apresentadas juntas na ilustração.

O segmento de comercialização congrega unidades que atuam como varejistas ou atacadistas. Essas diferentes modalidades também foram destacadas.

Cabe ressaltar que, dentro de uma cadeia de produção, os atores que atuam na compra e na venda de produtos são denominados intermediários. Utilizamos esta denominação com base em Mendes e Padilha Junior (2007, p. 218), que definem que os "intermediários são indivíduos ou organismos comerciais que se especializam na execução das diversas funções da comercialização relacionadas com atividades de compra e venda na medida em que as mercadorias se deslocam dos produtores até os consumidores".

\section{Descrição das cadeias produtivas nos municípios de Biguaçu-SC, Santa Rosa de Lima-SC e Bituruna-PR}

No sentido de compreender as cadeias como um todo, com base nos dados levantados nas entrevistas

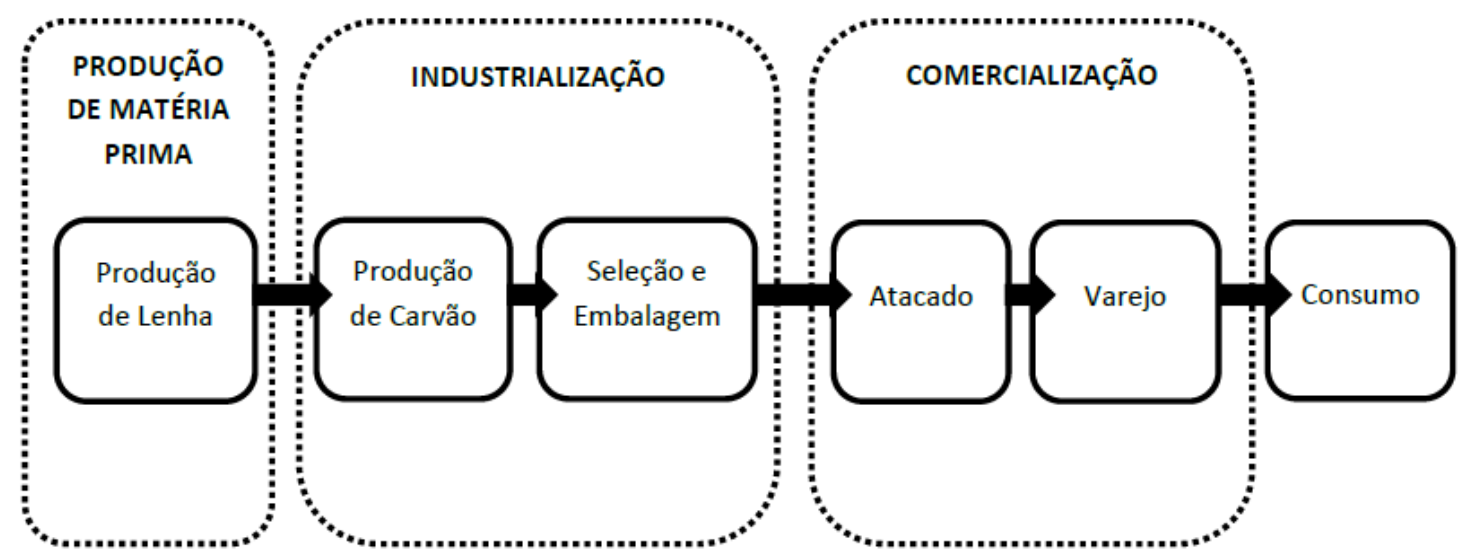

FIGURA 1 - Processos da cadeia produtiva do carvão vegetal.

FONTE: Elaborado pelos autores com base no trabalho de campo realizado entre outubro/2010 e março/2013. 
semiestruturadas, descreveremos as relações entre suas unidades socioeconômicas de produção e entre os seus atores. Com esta descrição, pretendemos alcançar a compreensão dos diferentes caminhos que o carvão vegetal percorre, desde a produção de matéria-prima até estar disponível ao consumidor, nos três estudos de caso.

Como já explicitado, no contexto de produção de carvão vegetal, entendemos que as unidades socioeconômicas de produção são os estabelecimentos dos agricultores e as empresas envolvidas nas etapas de produção de lenha, produção de carvão, seleção e embalagem, atacado, varejo e consumo. Estas unidades podem participar de uma ou mais etapas da cadeia, podendo estar inseridas nos três macrossegmentos ou em apenas num deles. As unidades, como, por exemplo, os estabelecimentos agrícolas, são formadas pelo trabalho de atores, que podem ter distintos perfis e podem atuar em diferentes pontos da cadeia.

Os tipos de atores de maior relevância identificados nas cadeias produtivas do carvão vegetal são:

1. Produtor de carvão vegetal: este pode produzir a matéria-prima para produção de carvão vegetal em seu próprio estabelecimento ou adquiri-la de terceiros.

2. Intermediário do carvão em embalagens informais: encontrado no município de Biguaçu, este intermediário adquire carvão de produtores e revende a estabelecimentos varejistas ou churrascarias, em embalagens informais.

3. Intermediário embalador (embalagens formais): atua comprando o carvão de produtores e embalando-o em embalagens formais. Este intermediário pode ser uma microempresa ou um produtor que venderá o carvão com nota fiscal de produtor rural. Estes poderão vender o carvão diretamente aos estabelecimentos varejistas, atuando também como distribuidores ou vender o carvão a um segundo intermediário.

4. Intermediário distribuidor: possui marca própria de carvão vegetal e paga ao intermediário embalador para que encha suas embalagens com carvão vegetal, de modo que o produto esteja pronto para distribuição nos estabelecimentos varejistas.
A Figura 2 representa os tipos de cadeia encontrados nos três estudos de caso, com as diferentes unidades presentes nas cadeias produtivas e seus encadeamentos a partir da produção de carvão vegetal.

A seguir, detalhamos cada um dos tipos de cadeia encontrados.

\subsection{Cadeias longas}

As cadeias longas foram encontradas nos três municípios, sendo caracterizadas pela presença de um intermediário que compra o carvão de diversos agricultores e o embala em embalagens formais destinadas aos estabelecimentos varejistas. Nesse processo, o carvão oriundo de diversos agricultores, produzido de forma distinta e, às vezes, de diferentes matérias-primas, é embalado sem distinção.

Os embaladores de Bituruna não pertencem à comunidade e por este motivo os extensionistas e produtores da região não se sentiram à vontade para nos apresentá-los. Nos municípios de Santa Rosa de Lima e de Biguaçu estes intermediários pertencem à comunidade e são produtores ou ex-produtores de carvão vegetal.

Há intermediários embaladores em Santa Rosa que compram carvão em municípios catarinenses próximos, como Rio Fortuna, São Bonifácio e São Martinho.

Os intermediários-embaladores buscam o carvão nos estabelecimentos dos agricultores em embalagens informais e, nas suas propriedades, o acondicionam em embalagens formais para comercialização.

Alguns intermediários-embaladores possuem Cadastro Nacional de Pessoa Jurídica (CNPJ) e estão organizados na forma de microempresa, outros não possuem este registro, podendo comercializar o carvão emitindo notas fiscais de produtor rural. No município de Biguaçu, todos os intermediários embaladores atuavam também na distribuição do carvão vegetal para os estabelecimentos varejistas ou consumidores finais em venda para churrascarias. Já nos municípios de Santa Rosa de Lima e de Bituruna, encontramos casos em que há mais um intermediário na cadeia, que é responsável por fazer a distribuição final do carvão. A Figura 3 representa as cadeias longas de produção encontradas nesta pesquisa. 


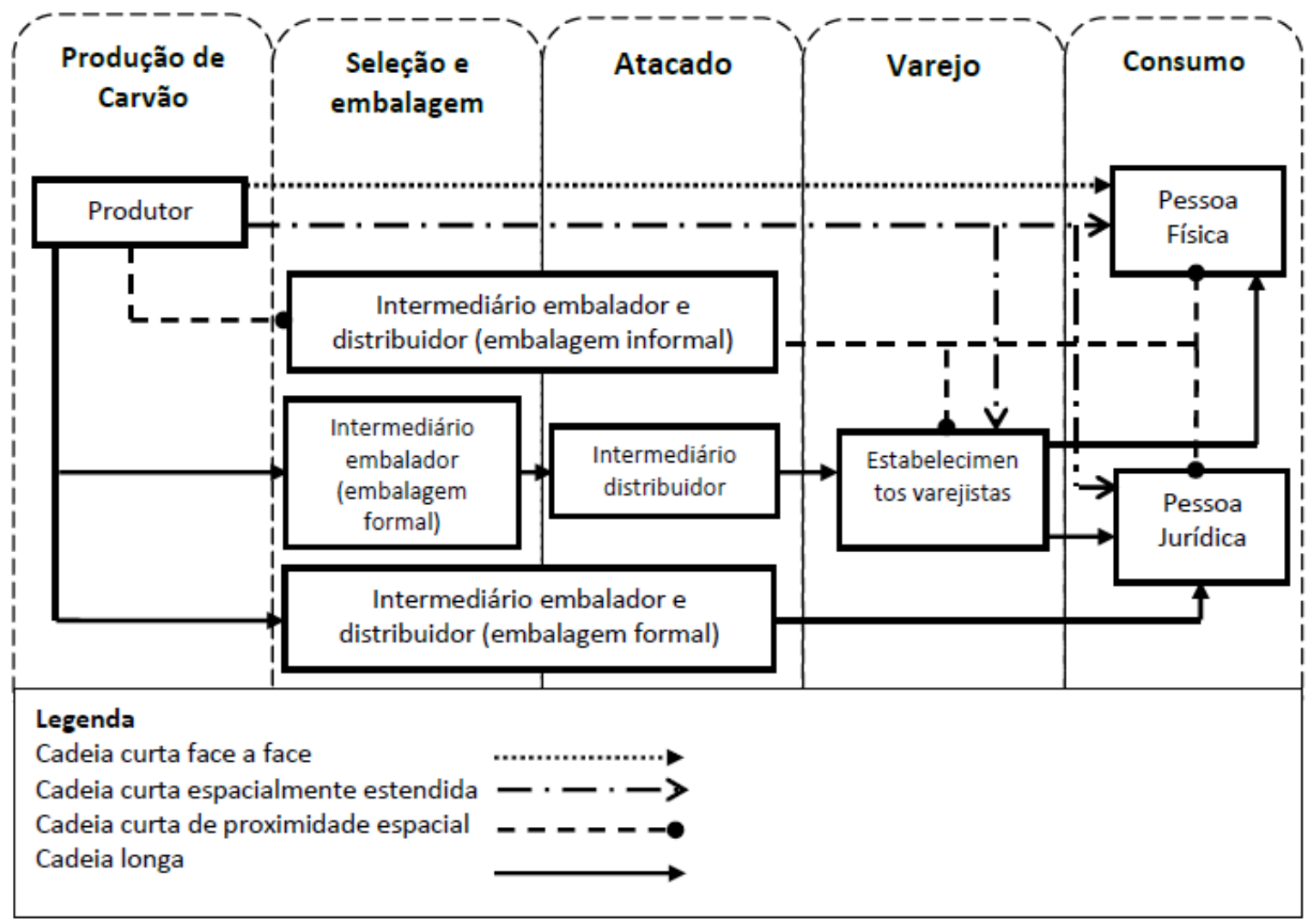

FIGURA 2 - Tipos de cadeias produtivas do carvão vegetal produzido nos municípios de Biguaçu, Bituruna e Santa Rosa de Lima. FONTE: Elaborado pelos autores com base no trabalho de campo realizado entre outubro/2010 e março/2013.

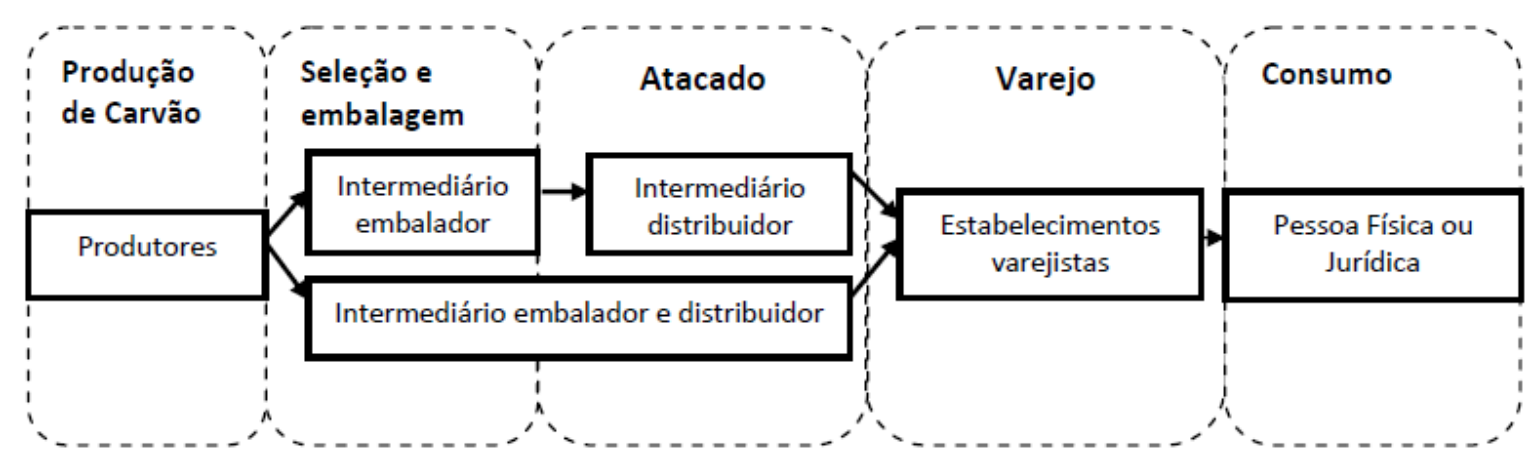

FIGURA 3 - Cadeias longas do carvão vegetal produzido nos municípios de Biguaçu, Bituruna e Santa Rosa de Lima. FONTE: Elaborado pelos autores com base no trabalho de campo realizado entre outubro/2010 e março/2013. 
A relação entre os intermediários-embaladores e intermediários-distribuidores costuma ocorrer da seguinte maneira: o embalador recebe as embalagens do distribuidor, realiza o processo de embalagem do carvão produzido por ele e/ou adquirido de produtores e entrega o carvão embalado e pronto para distribuição ao distribuidor. Os embaladores que vendem diretamente nos mercados já têm uma logística de distribuição do carvão, mas podem, eventualmente, negociar com um distribuidor, o que permite uma maior flexibilidade, pois, apesar de possuir uma embalagem própria, também embala carvão nas embalagens de terceiros.

Em alguns casos, apesar de o distribuidor mandar fazer as embalagens e fornecê-las ao embalador, os dados apresentados na embalagem são os dados do embalador. Os dados que comumente são encontrados em embalagens formais de carvão vegetal são: nome, telefone, números da inscrição estadual e do cadastro técnico do IBAMA.

Os intermediários-distribuidores identificados são atores externos às comunidades estudadas. No município de Santa Rosa de Lima, há relações com distribuidores dos municípios de Biguaçu, Gaspar, São Ludjero, Grão Pará e Tubarão, todos do Estado de Santa Catarina.

Estas cadeias de produção caracterizam-se como cadeias longas, pois, ao se utilizar carvões de diversos produtores, as marcas perdem a sua identidade com a origem e a forma de produção. Assim, o consumidor não tem elementos para identificar a origem do produto. Nestas cadeias, apesar de as embalagens serem formais, grande parte do carvão absorvido é produzido de forma não regularizada, pois, mesmo quando o carvão é feito de espécies exóticas ou com autorização de corte da mata nativa e com autorização para a atividade carvoeira, este acaba se misturando com o carvão produzido de forma irregular.

\subsection{Cadeia curta face a face}

A cadeia curta face a face, que ocorre quando o produtor rural vende seu produto diretamente ao consumidor, foi encontrada no município de Biguaçu, quando agricultores vendem seu produto diretamente na feira livre na sede do município de Florianópolis, em sacos reutilizados de cimento com aproximadamente $10 \mathrm{~kg}$. A Figura 4 apresenta, com detalhes, o modelo esquemático da cadeia curta de produção face a face identificada na região.

\subsection{Cadeia curta de proximidade espacial}

A cadeia curta de proximidade espacial foi encontrada no município de Biguaçu. Nesta cadeia, os produtores vendem o carvão para intermediários, que revendem o carvão nos estabelecimentos varejistas e consumidores, porém não em embalagens formais, o carvão é vendido a granel, nas embalagens reutilizadas de sacos de cimento. Nesta cadeia, o intermediário, da mesma forma que na cadeia longa, busca o carvão na propriedade do produtor. Seleciona e reembala, porém ainda em embalagens informais.

Por seu caráter informal, o carvão nos sacos de cimento não costuma ser transportado e comer-

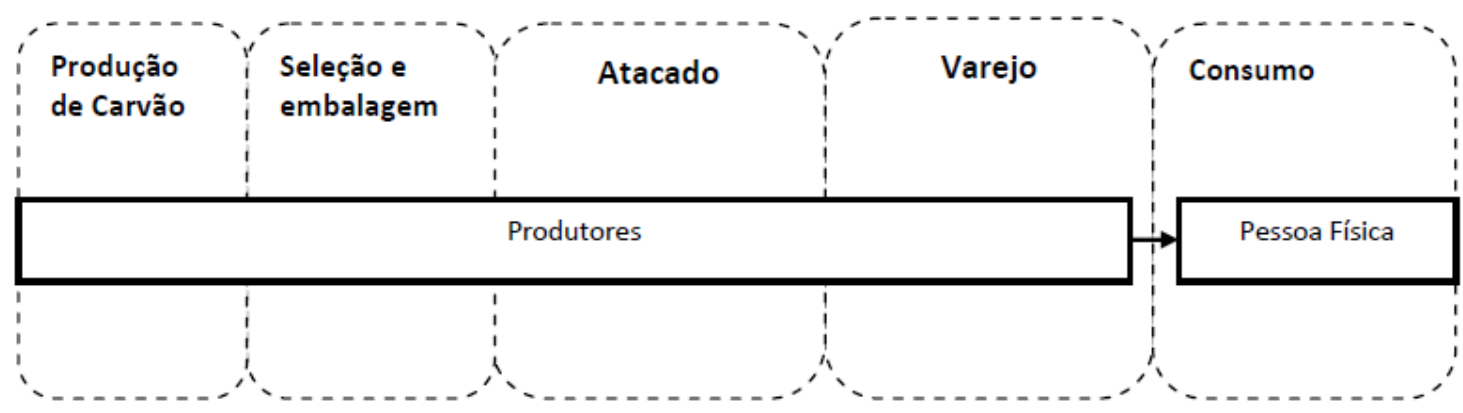

FIGURA 4 - Cadeia curta face a face do carvão vegetal produzido no município de Biguaçu-SC.

FONTE: Elaborado pelos autores com base no trabalho de campo realizado entre outubro/2010 e março/2013. 
cializado a grandes distâncias, sendo encontrado em estabelecimentos varejistas no município de Biguaçu e nos municípios vizinhos de São José e Florianópolis. O carvão nesta embalagem também não atinge alguns tipos de estabelecimentos, como supermercados e lojas de conveniência. Esta cadeia é considerada uma cadeia curta de produção, pois os estabelecimentos varejistas e os consumidores reconhecem a origem do produto, seu local de comercialização, forma de produção, e associam a característica informal do "carvão no saco de cimento" com características positivas de qualidade. A Figura 5, a seguir, ilustra a cadeia curta de proximidade espacial encontrada no município de Biguaçu.

\subsection{Cadeia curta espacialmente estendida}

A cadeia curta espacialmente estendida instituiu-se recentemente como resultado do estímulo de projetos de pesquisa e extensão desenvolvidos em Biguaçu, por meio de um grupo de produtores e intermediários do município que conseguiram sua regularização fundiária e ambiental e formaram a Associação Valor da Roça.

Neste caso, as embalagens de carvão, denominado pela marca coletiva "Nosso Carvão", contêm informações sobre o tipo de matéria-prima, sobre a forma de manejo da terra e sobre a regularização ambiental. Além das informações genéricas, a embalagem contém etiquetas de identificação individuais em que constam: nome do produtor, telefone, número da inscrição estadual de produtor rural, número do Cadastro Técnico Federal (registro no IBAMA), número da Autorização de Corte (AUC) que deu origem à matéria-prima e número da Certidão Ambiental ou da Licença Ambiental para a atividade de carvoejamento.

AAssociação controla a utilização dessa identidade por meio da certificação dos estabelecimentos rurais participantes, distribuição das embalagens e etiquetas de identificação individual. As regras de uso das embalagens estão estabelecidas no caderno de normas da Associação. A utilização correta da marca coletiva e a veracidade das informações constantes da embalagem são objeto de preocupação frequente da Associação. Qualquer usuário que cometer uma fraude, não cumprindo com o disposto no manual, estará maculando a marca Valor da Roça, que tem como premissa principal a responsabilidade social e ambiental e, portanto, estará sujeito às penalidades previstas no documento normativo.

Este é um caso de cadeia de produção que possui atributos que a qualificam como uma cadeia curta espacialmente estendida, pois as informações contidas na embalagem permitem que o consumidor tenha conhecimento da origem e da forma de produção do carvão, inclusive com informações sobre o produtor e a respeito da regularidade ambiental. Este é o único tipo de cadeia identificada onde todo o carvão é produzido e comercializado de forma legalizada. A Figura 6 representa a cadeia curta espacialmente estendida encontrada no município de Biguaçu.

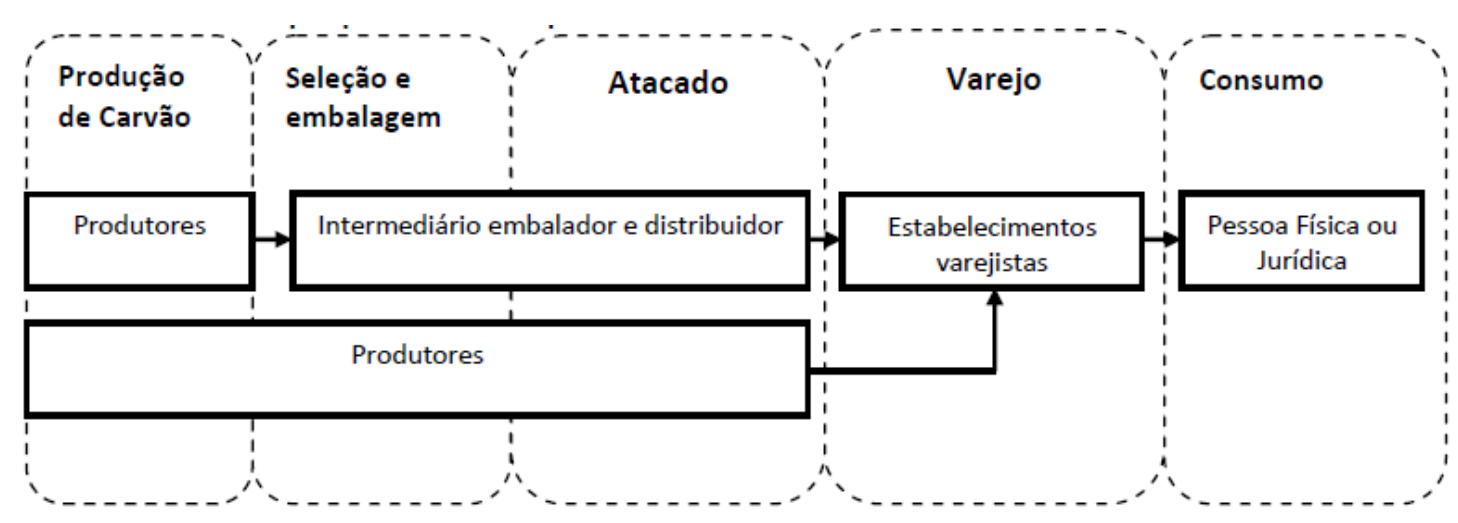

FIGURA 5 - Cadeia curta de proximidade espacial do carvão produzido no município de Biguaçu.

FONTE: Elaborado pelos autores com base no trabalho de campo realizado entre outubro/2010 e março/2013. 


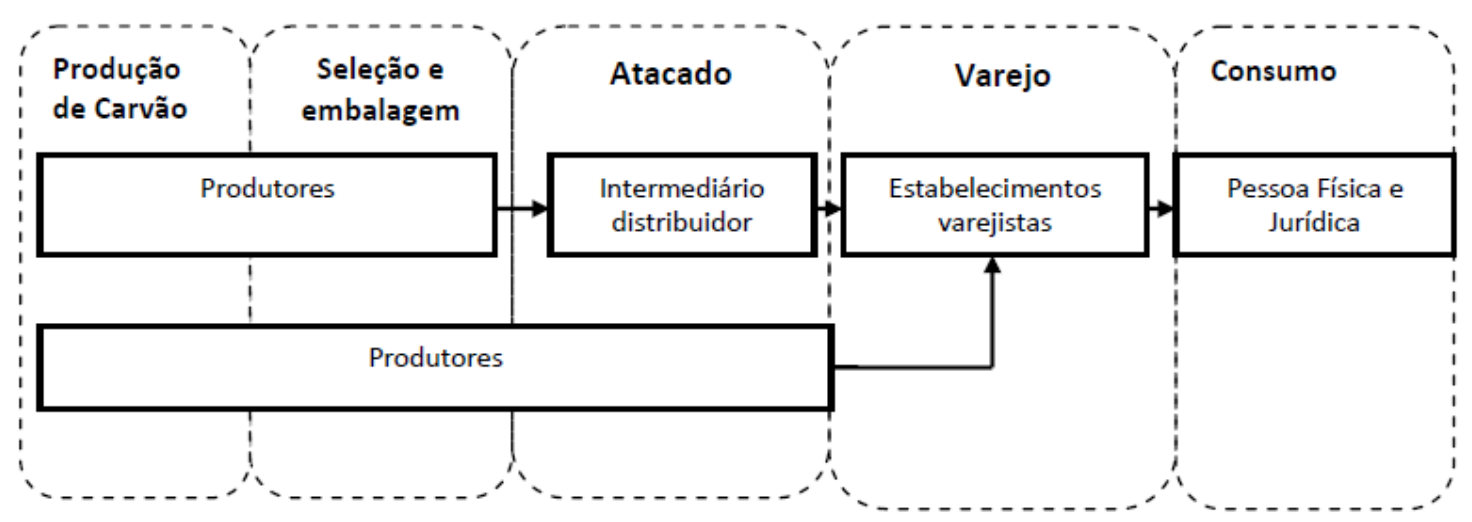

FIGURA 6 - Cadeia curta espacialmente estendida do carvão vegetal produzido no município de Biguaçu-SC.

FONTE: Elaborado pelos autores com base no trabalho de campo realizado entre outubro/2010 e março/2013.

\section{A relação entre os diferentes atores da cadeia produtiva do carvão vegetal}

No município de Biguaçu, o carvão era produzido e vendido para intermediários que embalavam e distribuíam o carvão vegetal. Em Santa Rosa de Lima, o carvão era primeiramente vendido a um intermediário que o embalava e, em seguida, a outro que o distribuía. Assim, em Santa Rosa de Lima, existia mais um agente na cadeia produtiva. O primeiro intermediário é um ator interno à comunidade, também produtor de carvão vegetal, já o segundo intermediário - o intermediário-distribuidor - é externo à comunidade e ao município.

Em Bituruna, entendemos que também há um intermediário a mais na cadeia, porém, tanto o intermediário-embalador quanto o intermediário-distribuidor são externos à comunidade.

Para Sproesser (2001), a relação dos produtores com os intermediários pode ser negativa ou positiva; pode contribuir para reduzir custos, regularizar e padronizar o fluxo de produtos junto ao consumidor e aumentar a produtividade no sistema agroalimentar. Entretanto, devido a um alto poder de barganha, os intermediários podem obter uma margem de lucro que não tem relação com a agregação de valor.

Acerca disso, verificamos que existem relações de confiança entre os agricultores e os intermediários. No município de Biguaçu, estas relações positivas, no sentido atribuído por Sproesser (2001), acontecem entre agricultores e intermediários, já que estes também vivem na comunidade e são produtores ou ex-produtores de carvão. E também entre os próprios intermediários, já que até tomam "carvão emprestado" entre si.

No município de Santa Rosa de Lima, estas relações positivas existem apenas entre produtores e embaladores, já que ambos vivem na mesma comunidade. Assim, os agricultores, no município de Santa Rosa de Lima, sobretudo no município de Biguaçu, valorizam o trabalho dos intermediários, reconhecendo o risco que estes têm em transportar grandes quantidades de carvão, já que, se forem pegos pela fiscalização, além da multa, perdem toda a mercadoria.

No município de Bituruna, entendemos que o carvão vegetal também pode passar por um agente a mais na cadeia de produção. Ou seja, é possível que o intermediário que faz o envasamento não faça a distribuição do carvão nos estabelecimentos varejistas. Porém, naquele município, não pudemos entrevistar os embaladores, pois, ao contrário do que ocorre em Santa Rosa de Lima, estes não são moradores da comunidade.

No município de Biguaçu, a relação entre agricultores e intermediários é de confiança e compromisso, em que detectamos normas implícitas que permitem o bom funcionamento do sistema como um todo. No município de Santa Rosa de Lima, esta característica de confiança também se aplica, mas em menor intensidade se comparada à observada em Biguaçu. Já em Bituruna, a relação 
entre produtores e intermediários é de dependência do primeiro em relação ao segundo.

Nos três estudos de caso, percebemos que as relações funcionam por meio de normas implícitas, já estabelecidas. Observamos, por exemplo, que o intermediário sempre deve fornecer a embalagem ao agricultor e, na maior parte dos casos, ele também busca o carvão na propriedade do agricultor. Foi possível identificar, também, exemplos claros de regras informais coibindo a ação oportunista, quando os custos de rompimento de um contrato, mesmo que informal, são maiores que os benefícios.

No município de Biguaçu, alguns agricultores se regularizaram e formaram a Associação Valor da Roça para comercialização do carvão vegetal e outros produtos por meio de marca coletiva. Além disso, estão associados alguns intermediários que também são produtores de carvão vegetal, fato que denota uma relação de confiança e parceria entre eles.

\section{Destino final e preço}

O destino final do carvão produzido em todas as cadeias de produção identificadas nesta pesquisa é o consumo doméstico ou em restaurantes, para utilização em churrascos, diferentemente do descrito nos trabalhos de Dias (2002) e Sincal et al. (2000), para os Estados de Minas Gerais e São Paulo, respectivamente, nos quais o destino era o setor industrial.

Os preços recebidos pelos produtores de carvão nesta pesquisa estão sistematizados na Tabela 1, separados por município.

No município de Biguaçu, onde encontramos mais de um tipo de cadeia, os preços não eram diferenciados entre elas, porém, podemos perceber que a existência das cadeias curtas face a face e de proximidade espacial influencia a definição do preço pago ao produtor no município. O preço recebido dos produtores da cadeia espacialmente estendida não está sistematizado nesta tabela, pois, para compará-lo com o das demais, seria preciso descontar os custos de beneficiamento que são, por exemplo, gastos com embalagem, alças e com o transporte. Apesar de não podermos comparar precisa- mente, os relatos destes agricultores nos indicam que a inserção dos produtores em mais uma etapa da cadeia de produção aumenta os seus ganhos líquidos.

TABELA 1 - Preço recebido pelo produtor por kg de carvão vegetal.

\begin{tabular}{cccc}
\hline & Biguaçu & Santa Rosa de Lima & Bituruna \\
\hline Preço R\$/kg & 0,45 & 0,33 & 0,23 \\
\hline
\end{tabular}

FONTE: Elaborada pelos autores com base no trabalho de campo realizado entre outubro/2010 e março/2013

Com base neste estudo, foi possível constatar que os agricultores de Bituruna são os que recebem menor valor pelo carvão vegetal. Este fato está relacionado com a menor inserção dos agricultores nas etapas da cadeia produtiva do carvão vegetal, pois os agricultores de Bituruna participam apenas da produção do carvão. Por sua vez, a falta de inserção está relacionada com as questões de regularização da atividade e de renda, que não serão aprofundadas neste trabalho.

Tanto no município de Biguaçu como no de Santa Rosa de Lima, existe maior autonomia dos agricultores na comercialização do produto, sendo que agricultores da própria comunidade, às vezes parentes ou vizinhos, fazem o beneficiamento (seleção e embalagem) e a distribuição do carvão nos mercados.

Em Biguaçu, pela proximidade do comércio informal, se torna mais viável para os agricultores insatisfeitos com os preços pagos distribuir o seu próprio carvão. Porém, há impedimentos para que isso ocorra normalmente, como a falta de tempo para se dedicar a mais este processo e outras dificuldades de logística, como, por exemplo, não possuir um caminhão ou carteira de habilitação.

Nos municípios de Biguaçu e de Santa Rosa de Lima, os agricultores conseguiram se inserir em mais de uma etapa da cadeia de comercialização, explicando assim os melhores preços pagos pelo produto. O motivo desta inserção, conforme já foi indicado neste estudo, foi diferente nestes dois municípios. Em Biguaçu, ocorreu por meio do mercado informal de carvão vegetal e em Santa Rosa ocorreu por meio de um maior acesso à informação e maiores condições de se adequarem às exigências legais. 


\section{Possibilidade de agregação de valor por meio da identificação de origem associada à qualidade, em cadeia curta de produção}

Segundo Waquil et al. (2010, p. 63), "a definição das características que podem representar qualidade é subjetiva, bem como a intensidade da associação destas características à sua mensuração e às próprias características de um bem ou serviço".

A qualidade do carvão vegetal está principalmente relacionada com o tipo de lenha usada como matéria-prima para produção de carvão. Os agricultores, nos três estudos de caso, costumam classificar as madeiras como moles ou duras. Segundo eles, as espécies de madeira "mais dura" fornecem um carvão "mais pesado", e o peso do carvão está diretamente relacionado com o seu poder calorífico, ou seja, com a durabilidade do fogo que fornece.

No município de Biguaçu, na cadeia curta de produção, os consumidores têm um canal direto com os produtores, sendo que este canal está diretamente relacionado à proximidade e ao caráter de informalidade. Carrieri-Souza (2010) identificou que os donos das churrascarias e dos mercados varejistas associam o carvão embalado no "saco de cimento" com características positivas, como alto poder calorífico e a baixa quebra dos agregados de carvão e reconhecem sua origem como sendo produzido por agricultores do município de Biguaçu. Já os gerentes dos mercados que compravam o carvão embalado formalmente não tinham conhecimento do local de origem nem da forma de produção do carvão vegetal.

No caso do município de Biguaçu, a cadeia curta está relacionada a um pequeno raio de distribuição do produto, porém, as cadeias curtas também podem ser do tipo expandida. A cadeia curta não implica necessariamente pequena abrangência da distribuição do produto, a identificação de origem pode acontecer por serviços de rastreabilidade ou, conforme exemplo da Associação Valor da Roça, de distinção das embalagens, de forma que o consumidor, mesmo estando distante, inclusive em país diferente do local de produção, possa conhecer seu local de origem e ter informações sobre sua forma de produção, como em uma cadeia curta espacialmente estendida.
Nesta pesquisa, identificamos que os preços pagos aos produtores eram melhores nos municípios em que, de alguma forma, agricultores produtores de carvão vegetal conseguiram se inserir nas etapas de seleção, embalagem e distribuição do produto. A partir de cadeias curtas de produção, o carvão vegetal é beneficiado pelos próprios produtores, que conferem identidade ao produto. Esta identidade pode ser trabalhada com base na qualidade do produto, mas deve, sobretudo, ser destacada com base nas condições ambientais e sociais desta produção e da produção de matéria-prima.

A diferenciação quanto à origem dos produtos diretamente ligada ao produtor rural proporciona a eles uma melhor inserção no mercado. Esse apontamento vai ao encontro do preceito de Mendes e Padilha Junior (2007), que afirmam que quando os produtores vendem os produtos sem distinção de marca e qualidade, de forma homogênea e sem nenhum grau de diferenciação, isso os torna tomadores de preços, ao invés de formadores de preço.

A cadeia curta de proximidade espacial encontrada no município de Biguaçu é, atualmente, uma cadeia irregular, porém cadeias curtas de proximidade espacial poderiam ocorrer com o carvão embalado em embalagens formais e totalmente regularizado, por exemplo, em festas ou feiras típicas na própria região de produção. Da mesma forma, a cadeia face a face é uma possibilidade para inserção dos agricultores, porém deve também ser regularizada.

A cadeia curta espacialmente estendida permite maior abrangência de venda da produção e nela se deve ter, ainda mais do que nos outros tipos de cadeia curta, sinalização inequívoca ao consumidor quanto à origem do produto e seu modo de produção, associada à possibilidade de rastreabilidade da identificação de sua origem. Estas condições são objeto de procura pelo consumidor que tem preocupação com a sustentabilidade da produção.

A diferenciação, a partir destes conceitos de qualidade e responsabilidade social e ambiental, em cadeias curtas de produção, permite a inserção dos agricultores e, consequentemente, permite que eles deixem a situação de tomadores de preço e passem a atuar na cadeia produtiva como formadores de preço. 


\section{Referências}

Batalha, M. O.; Silva, A. L. Gerenciamento de sistemas agroindustriais: definições, especificidades e correntes metodológicas. In: (Coord.). Gestão Agroindustrial. 3. ed., v. 1. São Paulo: Atlas, 2007. 770 p. p. 1-62.

Carrieri-Souza, M. Estudo exploratório sobre o sistema de produção e a comercialização do carvão vegetal produzido por agricultores familiares da microbacia de São Mateus (Biguaçu) $S C$ ). Florianópolis, TCC (Curso de Agronomia) - Centro de Ciências Agrárias, Universidade Federal de Santa Catarina, 2010. Disponível em: <http://www.tcc.cca.ufsc.br/agronomia/ ragr89.pdf $>$. Acesso em: 20/09/2013.

Dias, E. C.; Assunção, A. Á.; Guerra, C. B.; Prais, H. A. C. Processo de trabalho e saúde dos trabalhadores na produção artesanal de carvão vegetal em Minas Gerais, Brasil. Cadernos de Saúde Pública (FIOCRUZ), Rio de Janeiro-RJ, 18(1), 269278, 2002. Disponível em: <http://www.scielosp.org/pdf/csp/ v18n1/8163.pdf>. Acesso em: 18/07/2013.

Fantini, A. C.; Uller-Gómez, C.; Gartner, C.; Vicente, N. R.; Schlindwein, S. L.; Bauer, E.; Menezes, G. T. C.. Produção de carvão e de saberes na agricultura familiar de SC. Revista Agropecuária Catarinense, Florianópolis/SC, 23(3), 13-15, 2010. Disponível em: <http://www.epagri.sc.gov.br/files/ Rac80_nov2010.pdf>. Acesso em: 19/07/2013.

Food and Agriculture Organization of United Nations (FAOSTAT). Dados de produção anual de carvão vegetal para o Brasil. 2011. Disponível em: <http://faostat.fao.org>. Acesso em: 01/08/2011.

Instituto Brasileiro de Geografia e Estatística (IBGE). Sistema IBGE de Recuperação Automática (SIDRA). 2008. Tabela 289 (Fonte: Produção da Extração Vegetal e da Silvicultura, vários anos). Disponível em: <http://www.sidra.ibge.gov.br/ bda $/$ tabela/protabl.asp $\mathrm{c}=289 \& \mathrm{z}=\mathrm{t} \& \mathrm{o}=18 \& \mathrm{i}=\mathrm{P}>$. Acesso em: 01/08/2013.

Lindemann, R. H. Ensino de química em escolas do campo com proposta agroecológica: contribuições a partir da perspectiva freireana de educação. 1 v. Florianópolis, Tese (Doutorado) - Programa de Pós-Graduação em Educação Científica e Tecnológica, Universidade Federal de Santa Catarina, 2010. Disponível em: <http://www.dominiopublico.gov.br/pesquisa/
DetalheObraForm.do?select_action $=\&$ co_obra $=191950>$. Acesso em: 01/09/2013.

Marsden, T.; Banks, J.; Bristow, G. Food Supply Chain Approaches: exploring their role in rural development. Sociologia Ruralis, Oxford, 40(4), 424-438, 2000.

Mendes, J. T. G.; Padilha Junior, J. B. Agronegócio: uma abordagem econômica. São Paulo: Pearson Prentice Hall, 2007. 369 p.

Roese, Mauro. A metodologia do estudo de caso. Cadernos de Sociologia, Porto Alegre: PPGS-UFRGS, 9, 1998.

SINCAL - Sindicato do Comércio Varejista de Carvão Vegetal e Lenha do Estado de São Paulo; FCESP - Federação e Centro do Comércio do Estado de São Paulo; SEBRAE-SP - Serviço de Apoio às Micro e Pequenas Empresas de São Paulo. Relatório Final: diagnóstico sobre a cadeia produtiva de carvão vegetal e lenha do Estado de São Paulo. 2000. Disponível em: $<$ www.ipef.br/tecprodutos/procarvao/procarvao.pdfß . Acesso em: 13/09/2013.

Sproesser, R. L. Gestão estratégica do comércio varejista de alimentos. In: Batalha, M. (Coord.). Gestão agroindustrial. v. 1. GEPAI. São Paulo: Atlas, 2001. p. 215-261.

Steenbock, W. Domesticação de bracatingais: perspectivas de inclusão social e conservação ambiental. 281 f. Florianópolis, Tese (Doutorado em Recursos Genéticos Vegetais) - Centro de Ciências Agrárias, Universidade Federal de Santa Catarina, 2009. Disponível em: <https://repositorio.ufsc.br/bitstream/ handle/123456789/92470/267335.pdf? sequence=1>. Acesso em: 22/07/2013.

Uller-Gómez, C.; Gartner, C. Um caminho para conhecer $e$ transformar nossa comunidade. Relatório final de pesquisa vinculada ao TOR 23/2006. Florianópolis: EPAGRI/MB2, 2008. 111 p. Disponível em: <http://www.pergamum.udesc. br/dados-bu/000000/000000000015/000015CF.pdf > . Acesso em: 10/07/2013.

Waquil, P. D.; Miele, M.; Schultz, G. Mercados e comercialização de produtos agrícolas. Porto Alegre: Editora da UFRGS, 2010.

Yin, R. Estudo de caso: planejamentos e métodos. 3. ed. Porto Alegre: Bookman, 2005. 